\title{
Early effects of COVID-19 on US fisheries and seafood consumption
}

\author{
Easton R. White ${ }^{\mathrm{a}, \mathrm{b}}$, Halley E. Froehlich ${ }^{\mathrm{c}, \mathrm{d}}$, Jessica A. Gephart ${ }^{\mathrm{e}}$, Richard S. Cottrell ${ }^{\mathrm{f}}$, Trevor A. Branch ${ }^{\mathrm{g}}$, Rahul \\ Agrawal Bejarano $^{\mathrm{h}}$, Julia K. Baum ${ }^{\mathrm{i}}$ \\ ${ }^{\mathrm{a} B i o l o g y}$ Department, University of Vermont, Burlington, VT, 05405, USA; ${ }^{\mathrm{b}} \mathrm{Gund}$ Institute for Environment, \\ University of Vermont, Burlington, VT, 05405, USA; ' $E$ cology, Evolution, \& Marine Biology, University of \\ California, Santa Barbara, CA, 93106, USA; 'Environmental Studies, University of California, Santa Barbara, CA, \\ 93106, USA; ${ }^{\mathrm{e} D e p a r t m e n t ~ o f ~ E n v i r o n m e n t a l ~ S c i e n c e, ~ A m e r i c a n ~ U n i v e r s i t y, ~ W a s h i n g t o n ~ D C ~ 20016 ; ~}{ }^{\mathrm{f}}$ National \\ Center for Ecological Analysis and Synthesis, University of California, Santa Barbara, CA, 93101; ' \\ Aquatic and Fishery Sciences, Box 355020, University of Washington, Seattle, WA, 98195, USA; ${ }^{\text {hSchool of }}$ \\ Environment and Sustainability, University of Michigan, Ann Arbor, MI 48109, USA; 'Department of Biology, \\ University of Victoria, Victoria, British Columbia, V8W 2Y2, Canada \\ *Corresponding author: Easton R. White (Easton.White@uvm.edu)
}

\begin{abstract}
The United States seafood sector is susceptible to shocks, both because of the seasonal nature of many of its domestic fisheries and its global position as a top importer and exporter of seafood. However, many datasets that could inform science and policy during an emerging event do not exist or are only released months or years later. Here we synthesize multiple data sources from across the seafood supply chain, including unconventional real-time datasets, to show the relative initial responses and indicators of recovery during the COVID-19 pandemic. We synthesized news articles from January to September 2020 that reported effects of COVID-19 on the US seafood sector, including processor closures, shortened fishing seasons, and loss of revenue. Concerning production and distribution, we assessed past and present landings and trade data and found substantial declines in fresh seafood catches $(-40 \%)$, imports $(-37 \%)$ and exports $(-43 \%)$ relative to the previous year, while frozen seafood products were generally less affected. Google search trends and seafood market foot traffic data suggest consumer demand for seafood from restaurants dropped by upwards of $70 \%$ during lockdowns, with recovery varying by state. However, these declines were partially offset by an increase (270\%) in delivery and take-out service searches. Our synthesis of open-access datasets and media reports shows widespread, but heterogeneous, ramifications of COVID19 across the seafood sector, implying that policy-makers should focus support on states and sub-sectors most affected by the pandemic: fishery-dependent communities, processors, and fisheries and aquaculture that focus on fresh products.
\end{abstract}

Keywords: Aquaculture, COVID-19, Fisheries, Pulse disturbance, Shocks

\section{Introduction}

Shocks, or "black swan" events (Anderson et al., 2017), are a common feature of seafood systems and appear to be increasing in frequency (Gephart et al., 2016; Gephart et al., 2017; Cottrell et al., 2019). Seafood shocks can be triggered by fish stock collapses, aquaculture diseases, natural disasters, and oil spills, as well as broader, more disruptive anthropogenic conflicts or disasters, such as wars and state dissolution, where impacts may reach across multiple food sectors influencing the interdependencies among them (Cottrell et al., 2019; Gephart et al., 2017). There is often a mismatch between the short timescales in which policy decisions have to be made to respond to these sudden events and the longer term science and data collection that would ideally be available to inform such decisions. This is especially relevant for the seafood sector where data are not typically collected or released in 'realtime', but usually only available months or years later. The rate of availability of fisheries information stands in stark contrast to other fields, such as public health or meteorology, which are able to produce near real-time updates on developing or ongoing shocks (Zhang et al., 2019; Menni et al., 2020).

Despite some similarities to smaller shocks, the COVID-19 global pandemic has triggered larger, more unpredictable, and synchronous impacts felt throughout entire food supply chains, across multiple sectors, and at local and global scales. The COVID-19 pandemic has forced many governments to shut down large segments of their economies, including businesses, restaurants, and schools, at least temporarily, to promote social distancing 
and reduce infection rates (Hale et al., 2020; White \& Hébert-Dufresne, 2020, Althouse et al., 2020). Both COVID19 itself, and responses to it, have the potential to affect the seafood sector in multiple ways (FAO 2020, Bennett et al., 2020, Love et al., 2020a). For example, during fishing and processing, seafood workers and observers often work long hours in tightly confined working conditions (Syron et al., 2018), which can facilitate the spread of the disease. Social distancing policies could also reduce seafood demand, given that $65 \%$ of US spending ( $\$ 69.6$ billion in 2017) on seafood is in restaurants (Love et al., 2020b), and this could have the cascading effect of lowering overall seafood prices since restaurants pay premium values for seafood (Love et al., 2020b). Conversely, alternative seafood markets (e.g., community-based fisheries) may emerge (Stoll et al., 2020) or demand may increase for canned and frozen goods. Thus, COVID-19 has the potential to at least temporarily — and perhaps permanentlyalter seafood supply chains. From fisheries and aquaculture production to distribution and purchasing patterns, various facets of COVID-19 present a broad-scale natural experiment to examine how the different components of the seafood supply chain respond to and recover from a major system shock.

Although seafood sectors in countries around the world have likely been impacted by the COVID-19 shock, we focus here on the United States because of its importance to global fisheries, its geographic heterogeneity amongst states (which allows spatial comparisons), and data availability. The United States is the world's top importer and fourth largest exporter of seafood products (US Census Bureau 2020). In addition, the US seafood sector is heterogeneous between states in terms of production, processing, and demand, each with its own sub-sectors (NMFS 2018). Seafood production includes aquaculture and commercial, recreational, and subsistence fisheries, all of which varies by state. For instance, Alaska itself accounts for $58 \%$ of all US commercial fisheries landings, but other states like Massachusetts have higher value for seafood landed (NMFS 2018). In addition, the seafood pipeline also includes processing, distribution, and consumer demand. Indeed, domestic aquaculture production only accounts for $<1 \%$ of annual production, but imported farmed species are among the most consumed (e.g. salmon and shrimp) (NOAA 2020). Each of these sub-sectors will likely be affected differently by the fallout from COVID-19, especially given differences in responses to the pandemic across US states and at a federal level (Hale et al., 2020; White \& Hébert-Dufresne, 2020, Althouse et al., 2020, Froehlich et al., 2020).

Here, we synthesize data from five distinct sources to assess early signals of the effects of COVID-19 on across US fisheries and seafood sectors. The data sets include two traditional types of fisheries data (fish landings data, seafood imports and exports by product category) and three non-traditional real-time data sources: news articles, Google search trends (Bento et al., 2020) for seafood, and seafood market foot traffic. These data sources span multiple spatial and temporal scales as well as the entire seafood pipeline, from production to consumer demand. We highlight both the results of this data synthesis - which could help policymakers in the short term to focus efforts on those in the seafood sector with the greatest need, to inform plans to build more robust indicators for future shocks, and guide questions on what new modes of seafood supply may or should persist into the future - as well as on our general approach as a means of providing much-needed data to help inform evidence-based decisions during ongoing national and global shocks.

\section{Methods}

\section{Media reporting on COVID-19 and US seafood}

We examined two sets of news article databases. First, we used GDELT, a searchable database that continuously compiles media from around the world (https://www.gdeltproject.org/). We used the search terms "(covid OR coronavirus) AND (seafood OR fishery OR fisheries OR aquaculture) AND [list of all state and territory names]" to compile all articles from January 1st, 2020, to September 1st, 2020 for the USA. We then removed duplicate titles and summarized the total number of articles. We also pulled individual state count data using the same search terms and a single state name. Second, we assembled a database of a partial collection of news articles focused on responses to the COVID-19 pandemic affecting various parts of the fisheries and seafood sectors (Gephart et al., 2020). We coded each article for geographic location, the supply chain sector involved, the type of production, and the specific impact and species groups involved. This resulted in a total of 196 news articles focused on the USA (Gephart et al., 2020).

\section{Fisheries landings}

Landings data are often not publicly available for months or years. However, for highly regulated halibut (Hippoglossus stenolepis) and sablefish (Anoplopoma fimbria) fisheries in Alaska (Hilborn et al., 2020), weekly 
landings data are reported weekly at https://www.fisheries.noaa.gov/alaska/commercial-fishing/fisheries-catch-andlandings-reports. We used data for these two fisheries for the first 40 weeks of each year from 2017-2020.

\section{Foreign trade}

USA monthly seafood trade data (Customs Value, USD) comes from the US Customs and Border Protection (US Census Bureau 2020). We calculated year-over-year changes in imports and exports for July 2018 to August 2020, from trade data specific to fishery products destined for human consumption (data from all 6-digit codes within the 03 chapter of the Harmonized System Database https://www.usitc.gov). All frozen product forms were grouped together, as were all live, fresh or chilled products. Dried, salted, brined, prepared meals, fish meal and oils, and other miscellaneous preparations were excluded.

\section{Seafood market foot traffic}

We use foot traffic data from SafeGraph (https://www.safegraph.com/), a data company that aggregates anonymized location data from numerous applications in order to provide insights about physical places. We examined data specific to fish and seafood markets (NAICS code 445220), which includes some restaurants. We filtered out businesses that were mislabeled as seafood markets and those with less than 300 days of foot traffic data since the start of 2019. We followed SafeGraph's recommendations on normalizing data by dividing the number of daily visits by the number of devices present.

\section{Web searches}

On October 6, 2020, United States search trend data were extracted from Google Trends (https://trends.google.com) in the Food and Drink category for keyword web search terms of "seafood restaurant", "seafood recipe", "seafood delivery", "sushi take out" and, for comparative food system context, "bbq restaurant". We compared daily search patterns of the past five years during the time frame of January 1st to October 5, standardizing within each year.

\section{Results and discussion \\ Media reporting on COVID-19 and US seafood}

As early as January 2020, news articles focused on decreased international demand for some US seafood products (e.g., farmed geoduck, Maine lobster) caused by the lockdown in China during the initial COVID-19 outbreak, followed by increased domestic demand for frozen and shelf-stable products (e.g. canned tuna) as the outbreak spread in the USA and elsewhere (Fig. 1c). Other commonly-reported effects of COVID-19 on the US seafood industry include restrictions on travel of seasonal laborers, shifts in consumer demand, fishing seasons being cut short, aquatic farmers delaying outplanting, processing centers closing, and seafood workers contracting COVID-19. There have also been several reports of industry adaptation on the commercial side, including direct-to-consumer marketing (e.g. https://finder.localcatch.org/, Stoll et al., 2020) and community supported fisheries programs, reducing the complexity of the supply chain. Media reporting on these effects has varied across the USA with the Northeast, Pacific Northwest, and Alaska receiving the most coverage per capita (Fig. 1d). In addition, news articles have tended to focus on fisheries production and fresh seafood (Fig. 1g). Although most news articles were not species-specific, the species groups that were most commonly referenced were marine fishes, diadromous fishes (most notably salmon), and crustaceans (Fig. 1h).

\section{Fisheries landings}

Comparing two Alaskan fisheries, we found that prior to June, landings of halibut declined by $40 \%$, whereas sablefish was in line with previous years (WebFigure 2). These differences likely reflect processing differences between these two fisheries since $60 \%$ of halibut is sold fresh (and for $30 \%$ higher prices than frozen product), while almost all sablefish catch is frozen (NMFS, 2018). Therefore, although sablefish is typically sold in the export market, sablefish demand should be more reliable for processors given increased demand for frozen goods generally during the pandemic. This is also in line with news articles on increased demand for frozen seafood products within the USA, including Alaskan pollock (Gadus chalcogrammus) (Gephart et al., 2020). Research in the Northeastern USA shows a similar complicated picture of commercial fisheries (Smith et al., 2020). Some stocks had landings in line with previous years, including those most familiar to US consumers (e.g. haddock). Conversely, stocks targeted for exporting (e.g., monkfish) experienced declines in both landings and price (Smith et al., 2020). 


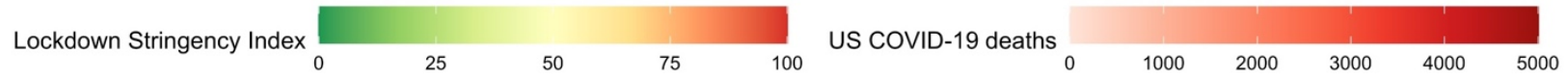

(a)

(b)

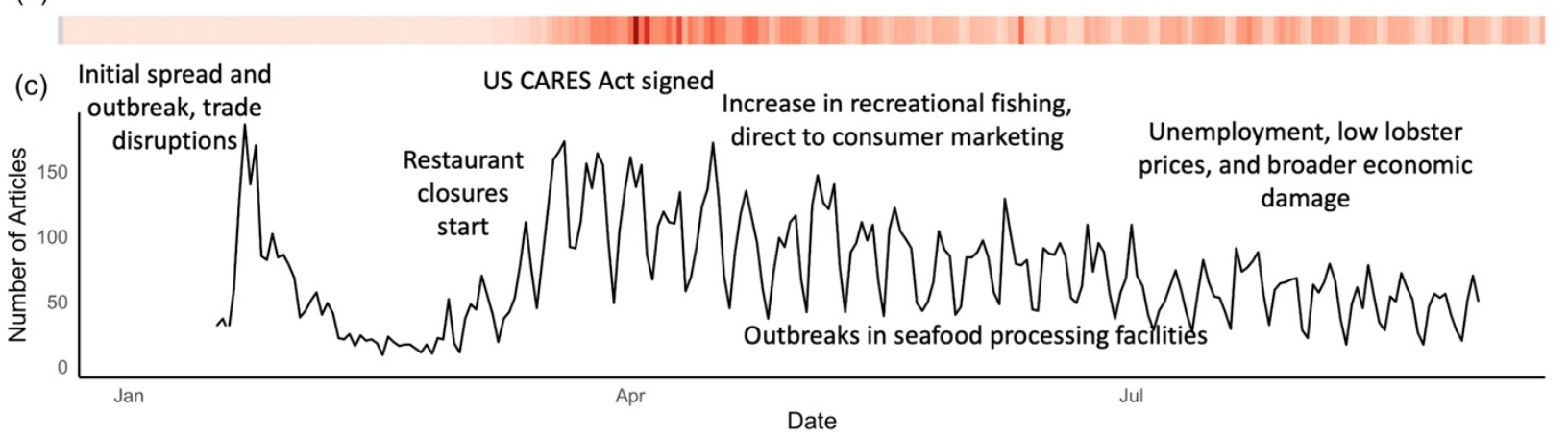

(d)

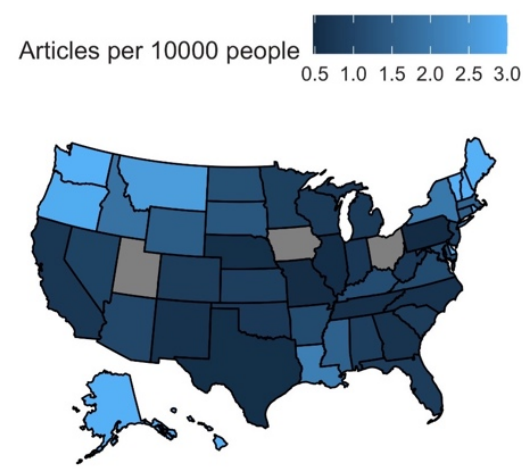

Production type

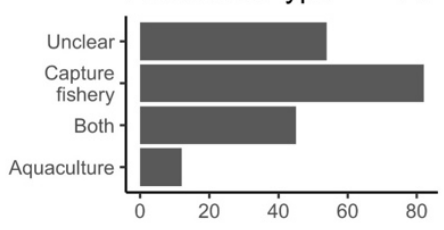

Product form

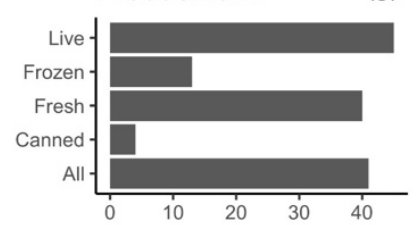

Production scale

(f)
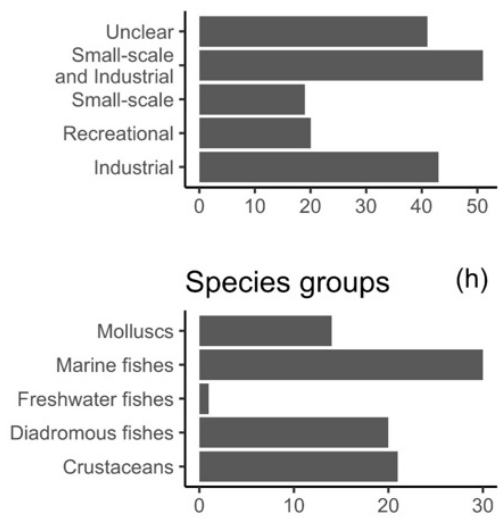

Figure 1. COVID-19 and associated media reports on seafood impacts in the USA (a) Government lockdown stringency index ("17 indicators aggregated reporting a number between 1 and 100 to reflect the level of government action", Hale et al., 2020), (b) COVID-19 related deaths per day in the US, and (c) the total number of news articles published per day (from GDELT database) with particular search terms (see Methods). (d) Distribution of COVID19 and seafood news articles per capita (from GDELT database) for each individual state since the start of the pandemic. (e-h) Distribution of impacts by production type, production scale, product form, and species groups affected. An impact is defined as explicitly reported on in a news article for our smaller ( $\mathrm{n}=196)$ manually-processed news database.

\section{Foreign trade}

Given the importance of the United States in global seafood trade (Gephart and Pace, 2015), disruptions to trade were among the earliest COVID-19 impacts felt outside of China. Comparing year-over-year import and export value, we found that prior to January 2020, seafood imports had stayed within $5 \%$ of the previous year's value, but then increased by $7-11 \%$ year-over-year in January and February 2020 . This increase may be explained by shipments originally heading to China being redirected to the US market (Gephart et al., 2020). Live, fresh, and chilled imports then fell to 37\% below the previous year's value by April 2020, while frozen products were only $3.5 \%$ below 2019 levels. Imports of both frozen and fresh products increased into August 2020, with frozen imports reaching 2019 levels and fresh imports leveling off at around 14\% below the previous year. Exports of frozen products declined from April to August to 39\% below the previous level, while exports of fresh products increased to $14 \%$ above 2019 levels in July, before dipping to 35\% below 2019 levels in August (Fig. 2). 
Possibly due to the trade war with China, exports of live, fresh and chilled products were generally lower than the previous year from April 2019 to September 2019 (-5 to -29\% year-over-year).

Coincident with the onset of COVID-19, exports sharply dropped to $29-43 \%$ below the previous year's value in February-April 2020 (Fig.

2). Exports of frozen fish were also generally below the previous year's values for most months of 2019 and at similar levels in January and February 2020, before a sudden drop to $20 \%$ below the previous year in March 2020. Frozen exports, however, returned to 4\% over the previous year's value in April 2020. In other words, domestic and foreign demand for frozen US seafood remained high in the first months of the pandemic.

\section{Seafood Market Foot Traffic}

The mean number of people visiting US fish and seafood markets ( $n=2,800$ with available data) decreased by $30 \%$ in 2020 as COVID19 cases started increasing (Figs. 3f, WebFigure 1). In total, 39 of the 41 states with sufficient data saw a decline in seafood market foot traffic from March 2019 to March 2020 (WebFigure 1). These widespread effects were most pronounced on both the east and west coasts. Some areas, particularly in the Southeast and Pacific Northwest have seen some recovery since June 2020 (WebFigure 1). This may be due to a combination of state-level differences in initial severity of COVID-19, social distancing restrictions, and subsequent reopening strategies (Hale et al., 2020; White \& Hébert-Dufresne, 2020, Althouse et al., 2020).

\section{Web Searches}

Google searches related to seafood in the USA increase on weekends and through the course of the year before peaking in mid-summer (Fig. 3). In 2020, searches for "seafood restaurant" declined by approximately $70 \%$ starting mid-March, well before the health impacts of the virus started sweeping across the U.S, but around the time the World Health Organization declared COVID-19 a global pandemic (March 11, 2020). This is not surprising given preemptive stay-at-home orders in some states, and the fact that $70 \%$ of spending on seafood in the USA is in restaurants (Love et al., 2020b). However, searches started rebounding in late April as individual states started reopening (Fig. 3a). During the same time period, searches for seafood delivery, takeout, and recipes continued to increase (average 270\%); although still at low relative magnitude (Figs. 3b-d), this change may indicate a new move towards different forms of local demand. Indeed, seafood restaurant and sushi take out searches have returned to comparable levels of previous years, while delivery and recipe searches are slightly higher.

\section{Conclusions}

The COVID-19 pandemic and resulting economic crisis represent a global scale disturbance that is being felt across all sectors, including seafood. In the USA, social distancing measures that have led to widespread restaurant closure and reduced seafood market foot traffic, have driven greater public dependence on seafood deliveries and homecooking. Such changes in consumer demand have profoundly affected seafood production, with landings, as well as imports and exports, generally changing in favor of frozen products. While frozen products appeared less affected than live and fresh products early on, trade of both product groups were generally below 2019 levels from February through June 2020 and exports of frozen products reached the lowest year-over-year value in August 2020. Given the inherent heterogeneity between seafood sub-sectors and state-level differences in COVID-19, these changes have not been felt equally across the U.S (Figs. 1d, S1, S3). These immediate responses and distribution changes are important in highlighting weak spots in seafood supply chains (such as fresh products or products with long supplychains being more disruption-prone), but also hide other aspects of exposure or adaptive capacity in the face of 

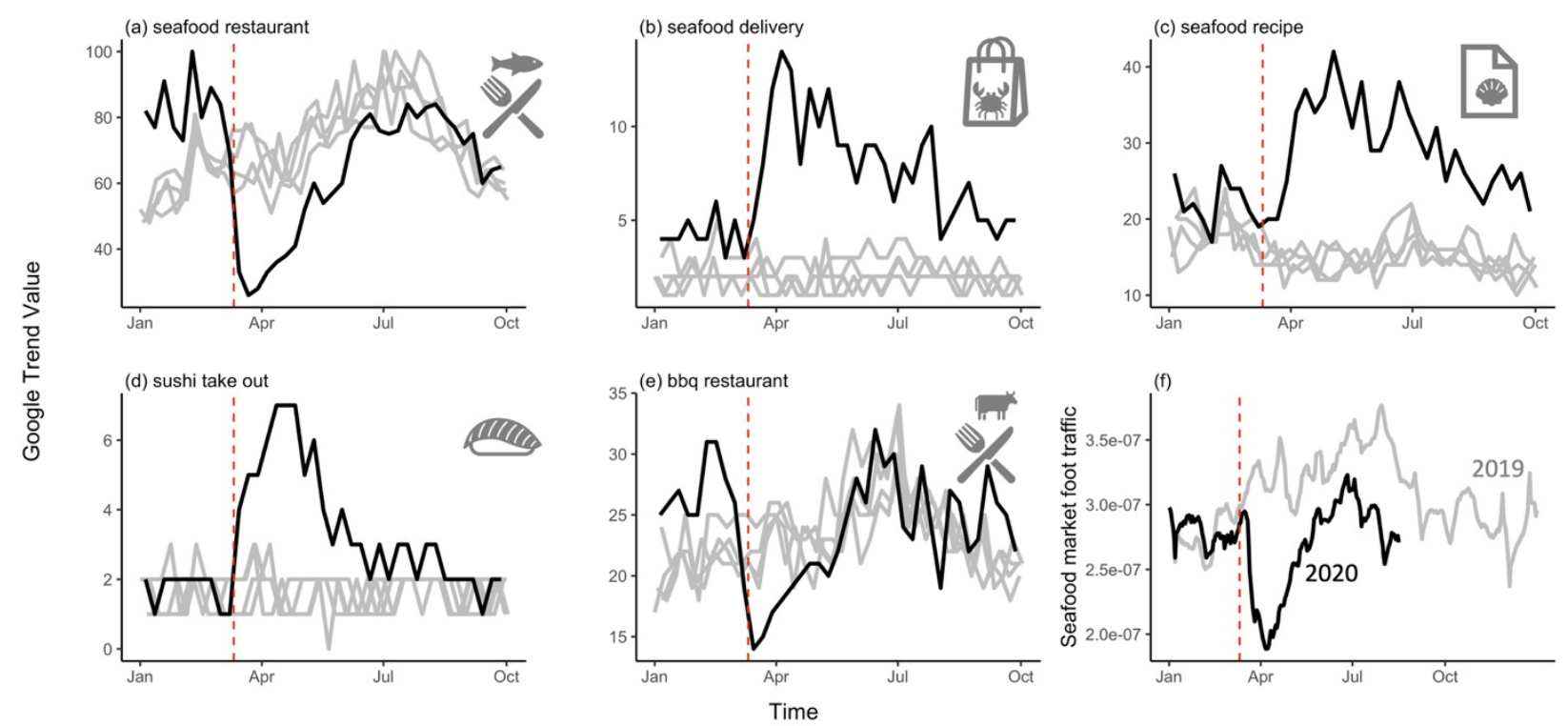

Figure 3. US seafood consumer demand. Previous and current relative Google trends for several search terms: (a) seafood restaurant, (b) seafood delivery, (c) seafood recipe, (d) sushi take out, and (e) bbq restaurant (as a control). Panel (f) is the rolling mean of normalized (see methods) foot traffic data for all US fish and seafood markets.

seafood shocks for different communities. Some states, notably in the Southeast and Pacific Northwest have seen faster recoveries in terms of seafood market demand (WebFigure 1), possibly due to differences in social distancing guidelines. Fishery-dependent communities have been, and will likely continue to be, hit especially hard by the fallout from COVID-19.

With such varied responses, only time will tell the full extent of COVID-19 on US fishing and seafood industries. A combination of human responses, combined with species life history, will determine the timescale of these effects and whether or not they are temporary or cause longer term shifts in consumption, fishing patterns, and fishery status. It is clear that we need better, and more timely reporting of both fisheries landings and aquaculture data for rapid policy interventions (Gephart et al., 2019; Froehlich et al., in revision). Fisheries like those in Alaska point to examples where weekly updates of publicly-available landings data can help inform science and policy. Although surveys of seafood workers were deployed during the pandemic (Smith et al., 2020; Stoll et al., 2020; van Senten et al 2020) these were often unplanned and lacked pre-pandemic baselines. These types of surveys should be a more regular component of government agencies in order to capture the full social and economic effects of shocks. In the absence of this data, our work shows how using non-traditional indicators (e.g. seafood market foot traffic) can help inform science and policy.

The varied responses by seafood sub-sectors and states also suggest priorities for government interventions. Amid the COVID-19 pandemic, there were three significant actions by the federal government. First, in direct response to fallout from COVID-19, the CARES relief act directed \$300 million to the seafood industry, though the distribution of these funds from the National Oceanic and Atmospheric Administration has reportedly been extremely slow, particularly for aquaculture (Gephart et al., 2020; van Senten et al., 2020). The federal government also purchased seafood directly, including 20 million pounds of shrimp ( $<1 \%$ total annual harvest) from Gulf of Mexico fishers (Gephart et al., 2020). While loans (e.g., Paycheck Protection Program) and heterogeneous State level support were made available, aquatic farmers cited Federal support as the most important relief to remain in business, highlighting a critical weak point in the current information and response structure for this sector (van Senten et al., 2020). Importantly, the stymied federal response to help the US seafood sector is not necessarily due to a lack of prioritization at the time. In fact, an expansive Executive Order was introduced to promote fisheries and aquaculture regulatory reform and increase production (Froehlich et al., in revision), occurring shortly after the time period 
(April 22-29) when seafood restaurant searches and foot traffic values were at their lowest point. Given the disruption and uncertainty, future interventions and funds for the US seafood sector should focus on fishery dependent communities, improving processing infrastructure and safety, supporting systems that focus on fresh seafood products, and more broadly data collection and management to create a system which can more readily respond and distribute relief more quickly. The implementation of these various governmental policies, combined with the continued and possible future interventions to COVID-19, will ultimately determine the long-term effects on the US seafood industry.

By their very nature, shocks are unanticipated and therefore difficult to study. The COVID-19 pandemic has highlighted long-standing mismatches in the protracted nature of typical fisheries and seafood data availability and the shorter time scale required for effective policy actions. Although often collected on daily or weekly timescales, landings and production data need to be released publicly on shorter time scales in order to be helpful to both scientists and policy-makers. Other data on consumer demand and the well-being of seafood workers should be collected more regularly and be more widely available to provide important information for policy-makers and policy-relevant science before and during shocks. In addition, delays in publishing of scientific findings can also impede policy actions, highlighting the role in releasing preliminary results through venues such as preprint servers (Eisen et al., 2020). Further, the National Oceanic and Atmospheric Administration has cancelled many research cruises and has waived requirements for fisheries observers on all of its boats (with some redeployment of observers in the Northeast starting August 14th), which limits current and future assessments on the status of commercially fished species (Gephart et al., 2020). Lastly, the COVID-19 pandemic has highlighted weaknesses along the seafood production pipeline. As a whole the US seafood industry relies heavily on imports and exports. Seafood processing centers have been a hotspot of COVID-19 cases and have consequently become a bottleneck for producers.

Alternative seafood networks and distribution, including straight to consumer local sales, have shown some promise in providing resilience during the current pandemic (Stoll et al., 2020) and for adapting to future seafood shocks.

\section{Acknowledgments}

E.R.W. was supported in part by the COVID-19 Rapid Research Fund from the Gund Institute for Environment at the University of Vermont. H.E.F. recognizes support from the University of California, Santa Barbara. T.A.B. was funded in part by the Richard C. and Lois M. Worthington Endowed Professor in Fisheries Management. J.K.B. was supported by a Natural Sciences and Engineering Council of Canada Discovery Grant and E.W.R. Steacie Fellowship. RSC acknowledges funding from the National Center for Ecological Analysis and Synthesis, University of California, Santa Barbara.

\section{Data and Code Availability}

Except for the SafeGraph foot traffic data, all data and code used in this paper are available at https://github.com/eastonwhite/COVID19 US Fisheries with the news article code at https://github.com/rahulAgrBej/seafoodGDELT.

\section{References}

1. Althouse, B. M., Wallace, B., Case, B., Scarpino, S. V., Berdhal, A., White, E. R., \& Hebert-Dufresne, L. (2020). The unintended consequences of inconsistent pandemic control policies. MedRxiv. https://doi.org/10.1101/2020.08.21.20179473

2. Anderson, S. C., Branch, T. A., Cooper, A. B., \& Dulvy, N. K. (2017). Black-swan events in animal populations. Proceedings of the National Academy of Sciences. https://doi.org/10.1073/pnas.1611525114

3. Bennett, N. J., Finkbeiner, E. M., Ban, N. C., Belhabib, D., Jupiter, S. D., Kittinger, J. N., Mangubhai, S., Scholtens, J., Gill, D., \& Christie, P. (2020). The COVID-19 Pandemic, Small-Scale Fisheries and Coastal Fishing Communities. Coastal Management, 1-11. https://doi.org/10.1080/08920753.2020.1766937

4. Bento, A. I., Nguyen, T., Wing, C., Lozano-Rojas, F., Ahn, Y.-Y., \& Simon, K. (2020). Evidence from internet search data shows information-seeking responses to news of local COVID-19 cases. Proceedings of the National Academy of Sciences, 202005335. https://doi.org/10.1073/pnas.2005335117

5. Cottrell, R. S., Nash, K. L., Halpern, B. S., Remenyi, T. A., Corney, S. P., Fleming, A., Fulton, E. A., Hornborg, S., Johne, A., Watson, R. A., \& Blanchard, J. L. (2019). Food production shocks across land and sea. Nature Sustainability, 2(2), 130-137. https://doi.org/10.1038/s41893-018-0210-1

6. Eisen, M. B., Akhmanova, A., Behrens, T. E., \& Weigel, D. (2020). Peer Review: Publishing in the time of COVID-19. Elife, 9, e57162 
7. FAO. (2020). How is COVID-19 affecting the fisheries and aquaculture food systems. Rome: FAO. http://www.fao.org/3/ca8637en/ca8637en.pdf

8. Gephart, J. A., Cottrell, R. S., Froehlich, H., Nussbaumer, E., Stoll, J. S., \& White, E. R. (2020). Covid-19 Seafood Impacts (1.0) [Data set]. Zenodo. https://doi.org/10.5281/ZENODO.3866189

9. Gephart, J. A., Deutsch, L., Pace, M. L., Troell, M., \& Seekell, D. A. (2017). Shocks to fish production: Identification, trends, and consequences. Global Environmental Change, 42, 24-32. https://doi.org/10.1016/j.gloenvcha.2016.11.003

10. Gephart, J. A., Froehlich, H. E., \& Branch, T. A. (2019). Opinion: To create sustainable seafood industries, the United States needs a better accounting of imports and exports. Proceedings of the National Academy of Sciences, 116(19), 9142-9146. https://doi.org/10.1073/pnas.1905650116

11. Gephart, J. A., \& Pace, M. L. (2015). Structure and evolution of the global seafood trade network. Environmental Research Letters, 10(12), 125014. https://doi.org/10.1088/1748-9326/10/12/125014

12. Gephart, J. A., Rovenskaya, E., Dieckmann, U., Pace, M. L., \& Brännström, Å. (2016). Vulnerability to shocks in the global seafood trade network. Environmental Research Letters, 11(3), 035008. https://doi.org/10.1088/1748-9326/11/3/035008

13. Hale, T., Webster, S., Petherick, A., Phillips, T., \& Kira, B. (2020). Oxford COVID-19 Government Response Tracker, Blavatnik School of Government.

14. Hilborn, R., Amoroso, R. O., Anderson, C. M., Baum, J. K., Branch, T. A., Costello, C., de Moor, C. L., Faraj, A., Hively, D., Jensen, O. P., Kurota, H., Little, L. R., Mace, P., McClanahan, T., Melnychuk, M. C., Minto, C., Osio, G. C., Parma, A. M., Pons, M., ... Ye, Y. (2020). Effective fisheries management instrumental in improving fish stock status. Proceedings of the National Academy of Sciences, 117(4), 2218-2224. https://doi.org/10.1073/pnas.1909726116

15. Love, D., Allison, E. H., Asche, F., Belton, B., Cottrell, R. S., Froehlich, H. E., Gephart, J. A., Hicks, C., Little, D. C., Nussbaumer, E. M., da Silva, P. P., Poulain, F., Rubio, A., Stoll, J. S., Tlusty, M. F., ThorneLyman, A. L., Troell, M., \& Zhang, W. (2020). Emerging COVID-19 impacts, responses, and lessons for building resilience in the seafood system. OSF Preprints. https://doi.org/10.31235/osf.io/x8aew

16. Love, David C., Asche, F., Conrad, Z., Young, R., Harding, J., Nussbaumer, E. M., Thorne-Lyman, A. L., $\&$ Neff, R. (2020). Food Sources and Expenditures for Seafood in the United States. Nutrients, 12(6), 1810. https://doi.org/10.3390/nu12061810

17. Love, David Clifford, Pinto da Silva, P., Olson, J., Fry, J. P., \& Clay, P. M. (2017). Fisheries, food, and health in the USA: The importance of aligning fisheries and health policies. Agriculture \& Food Security, 6(1), 16. https://doi.org/10.1186/s40066-017-0093-9

18. Menni, C., Valdes, A. M., Freidin, M. B., Sudre, C. H., Nguyen, L. H., Drew, D. A., Ganesh, S., Varsavsky, T., Cardoso, M. J., El-Sayed Moustafa, J. S., Visconti, A., Hysi, P., Bowyer, R. C. E., Mangino, M., Falchi, M., Wolf, J., Ourselin, S., Chan, A. T., Steves, C. J., \& Spector, T. D. (2020). Realtime tracking of self-reported symptoms to predict potential COVID-19. Nature Medicine, 26(7), 10371040. https://doi.org/10.1038/s41591-020-0916-2

19. National Marine Fisheries Service. (2018). Fisheries of the United States, 2017 Report. U.S. Department of Commerce, NOAA Current Fishery Statistics No. 2017, https://www.fisheries.noaa.gov/resource/document/fisheries-united-states-2017-report

20. Smith, S., Golden, A., Ramenzoni, V., Zemeckis, D. R., \& Jensen, O. P. (2020). Adaptation and resilience of commercial fishers in the Northeastern United States during the early stages of the COVID-19 pandemic. OSF Preprints. https://doi.org/10.31235/osf.io/z3v2h

21. Stoll, J. S., Harrison, H. L., De Sousa, E., Callaway, D., Collier, M., Harrell, K., Jones, B., Kastlunger, J., Kramer, E., Kurian, S., Lovewell, A., Strobel, S., Sylvester, T., Tolley, B., Tomlinson, A., White, E. R., Young, T., \& Loring, P. A. (2020). Alternative seafood networks during COVID-19: Implications for resilience and sustainability. EcoEvoRxiv. https://doi.org/10.32942/osf.io/kuzwq

22. Syron, L. N., Lucas, D. L., Bovbjerg, V. E., Case, S., \& Kincl, L. (2018). Occupational traumatic injuries among offshore seafood processors in Alaska, 2010-2015. Journal of Safety Research, 66, 169-178. https://doi.org/10.1016/j.jsr.2018.07.008

23. US Census Bureau. (2020). Harmonized system district level data. www.usa trade.census.gov

24. van Senten, J., Smith, M. A., \& Engle, C. R., (2020). Impacts of COVID-19 on U.S. Aquaculture, Aquaponics, and Allied Businesses. Survey Report. COVID-19 Survey. Virginia Tech: https:////www.arec.vaes.vt.edu/content/arec_vaes_vt_edu/en/arec/virginiaseafood/research/Impacts_of_COVID19.html 
25. White, E.R., \& Hébert-Dufresne L., (2020) State-level variation of initial COVID-19 dynamics in the United States. PLoS One, 15(10), e0240648. https://doi.org/10.1371/journal.pone.0240648

26. Zhang, X., Su, Z., Lv, J., Liu, W., Ma, M., Peng, J. and Leng, G., (2019). A set of satellite-based near realtime meteorological drought monitoring data over China. Remote Sensing, 11(4), 453 


\title{
Supplemental Material for
}

\section{Early effects of COVID-19 on US fisheries and seafood consumption}

\author{
Easton R. White ${ }^{\mathrm{a}, \mathrm{b}}$, Halley E. Froehlich ${ }^{\mathrm{c}, \mathrm{d}}$, Jessica A. Gephart ${ }^{\mathrm{e}}$, Richard S. Cottrell ${ }^{\mathrm{f}}$, Trevor A. \\ Branch $^{\mathrm{g}}$, Rahul Agrawal Bejarano ${ }^{\text {, }}$ Julia K. Baum ${ }^{\mathrm{i}}$
}

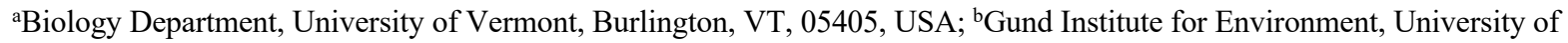
Vermont, Burlington, VT, 05405, USA; 'Ecology, Evolution, \& Marine Biology, University of California, Santa Barbara, CA, 93106, USA; ' Environmental Studies, University of California, Santa Barbara, CA, 93106, USA; 'Department of Environmental

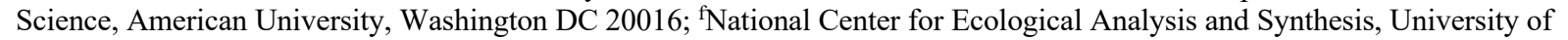

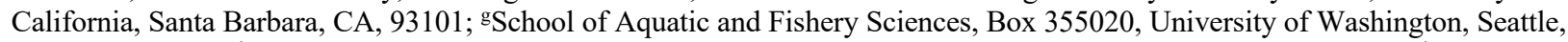
WA, 98195, USA; h' School of Environment and Sustainability, University of Michigan, Ann Arbor, MI 48109, USA; ${ }^{i}$ Department of Biology, University of Victoria, Victoria, British Columbia, V8W 2Y2, Canada
\end{abstract}

*Corresponding author: Easton R. White (Easton.White@uvm.edu)

WebFigure 1. Proportional change (for 2020 compared to same time period in 2019) state-level monthly mean of normalized (see Methods) foot traffic data for fish and seafood markets. A percent change of 0.8 in April for a state would indicate a 20\% decline in foot traffic from April 2019 to April 2020.

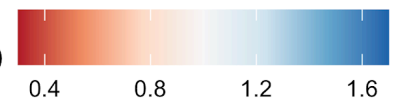

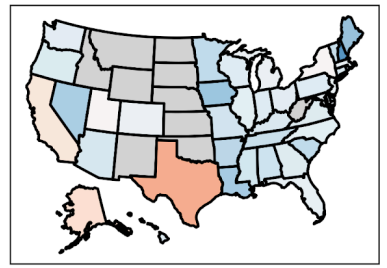

January

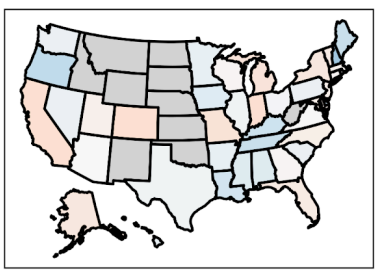

February

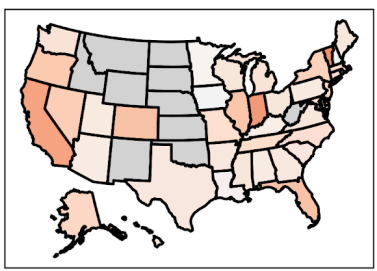

March

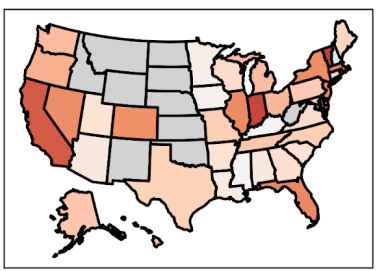

April

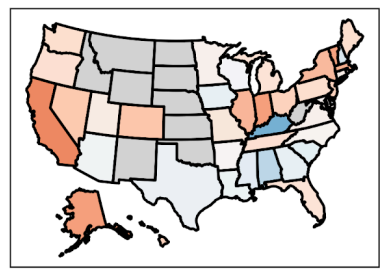

May

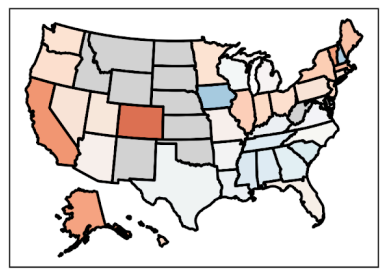

June

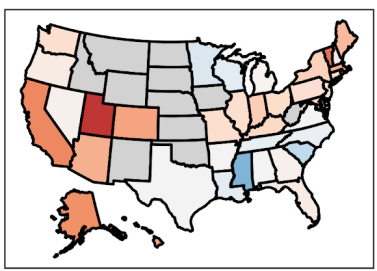

July

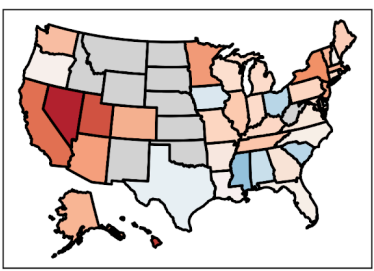

August 
WebFigure 2. Alaskan weekly landings (pounds) for halibut (Hippoglossus stenolepis) and sablefish (Anoplopoma fimbria) for 2020 (black line) and past years (grey lines). Data is updated at https://www.fisheries.noaa.gov/alaska/commercial-fishing/fisheries-catch-and-landings-reports.

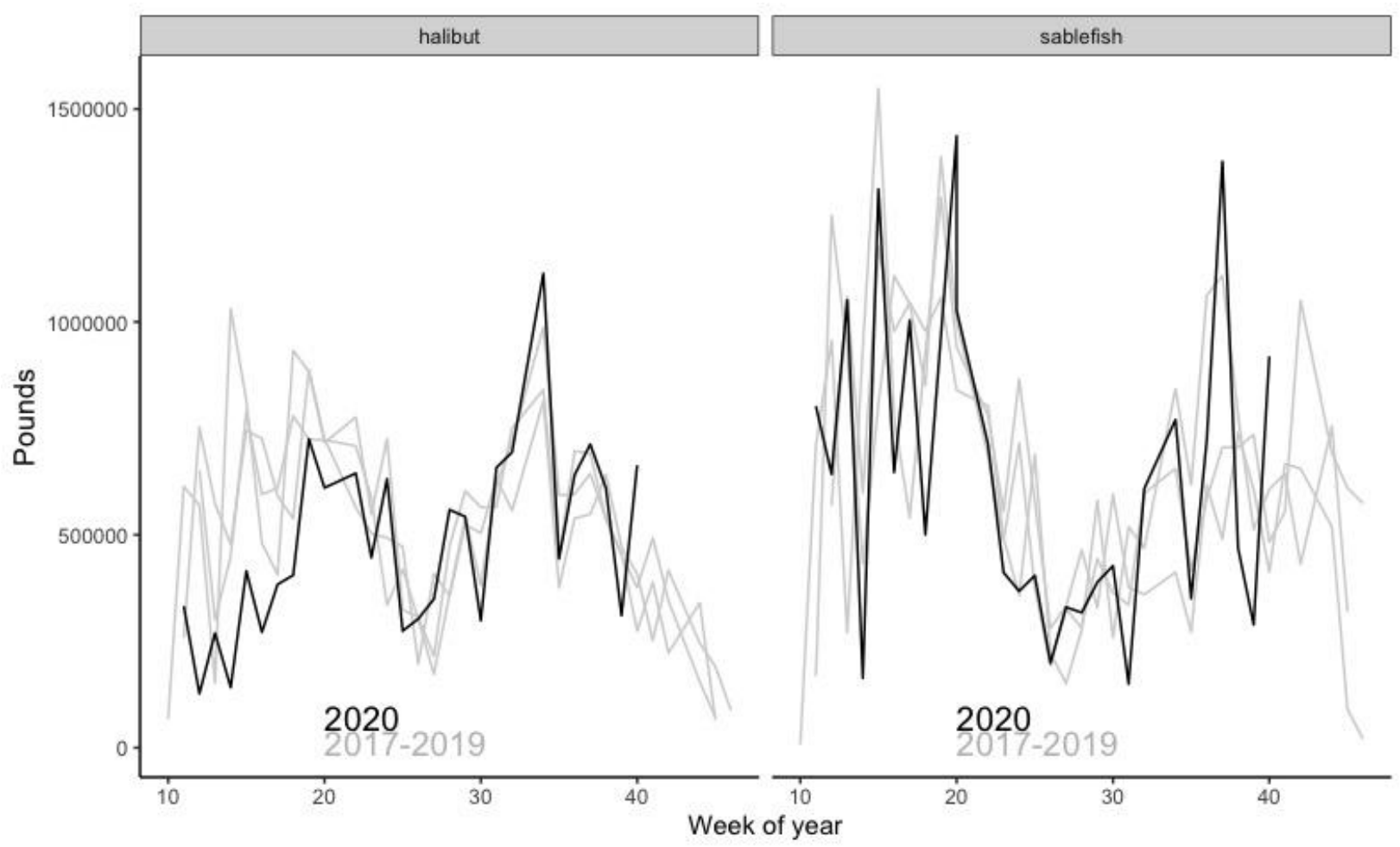


WebFigure 3. State-level monthly number of news articles published for search terms "(covid OR coronavirus) AND (seafood OR fishery OR fisheries OR aquaculture) AND [list of all state and territory names]".

No. of articles per 10000 people
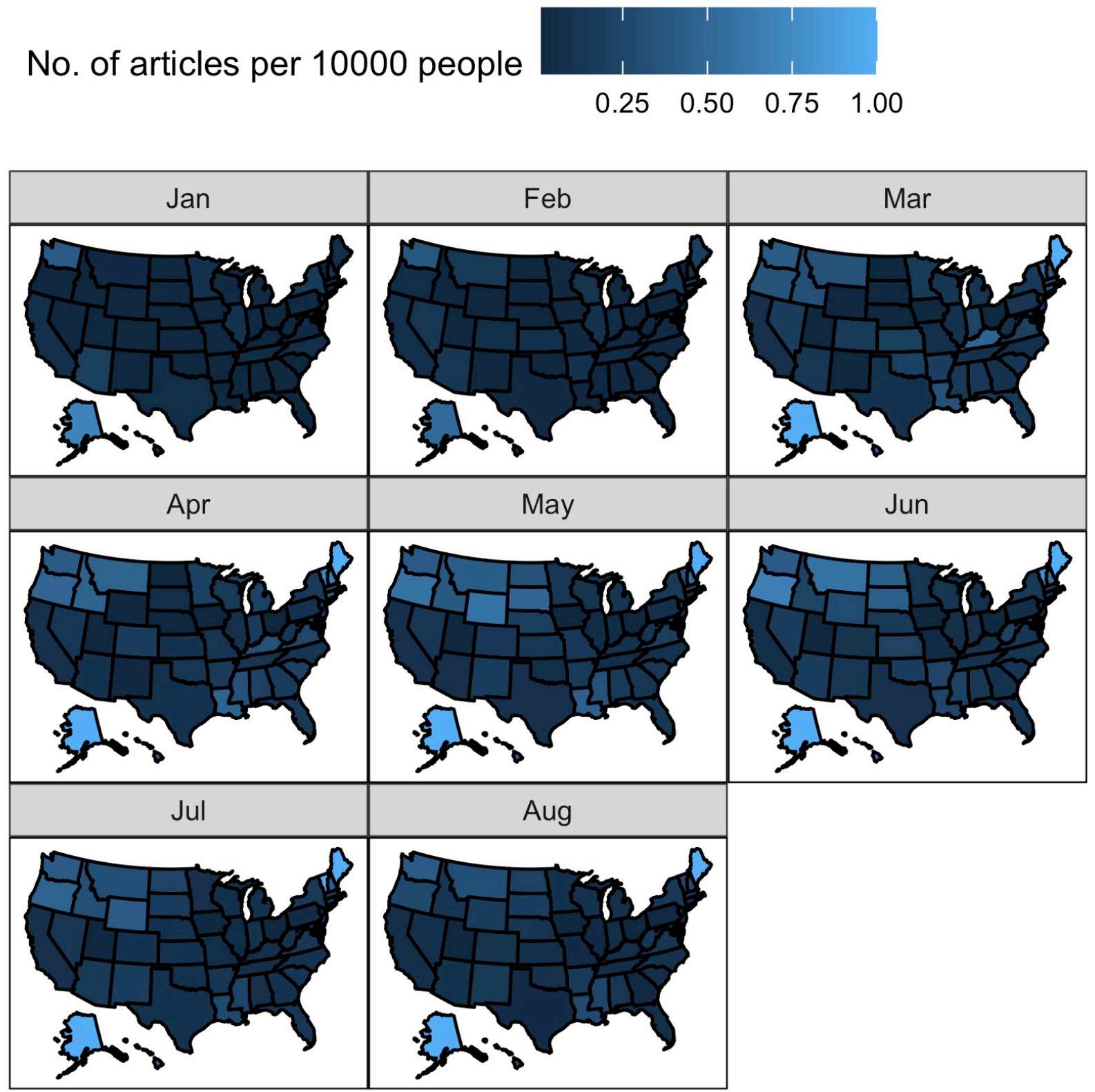